\title{
Design e Dissidência Queer: considerações sobre questões de gênero no design
}

Mariana Nobre de Oliveira;

Wellington Gomes de Medeiros

resumo:

Este artigo apresenta considerações sobre design e a cultura queer como parte de pesquisa em desenvolvimento. Inicialmente, contextualizamos sobre as políticas de gênero contemporâneas, apresentando questões sobre a ordem binária, as hierarquias de gênero, e a pluralidade dos ativismos, pontuando também de que forma essas questões se relacionam com o campo do design. Tratamos das dissidências de gênero como intrínsecas às relações de interseccionalidade e decolonialidade, direcionando o design como um meio político de contestação para enfrentamento das pautas e perspectivas queer. Colocamos em discussão os regimes estéticos normativos e o modo como o design opera frente aos padrões hegemônicos, apresentando novas propostas e perspectivas que vêm ocorrendo no campo. A intenção é perceber, na ascensão dos novos discursos, a inevitabilidade das questões de gênero no design pelo seu papel e impacto nas representações simbólicas de gênero e na materialização de regimes normativos. Considerar o fator humano em sua complexidade impõe, pelas vias da contemporaneidade, uma nova ótica sobre as dissidências de gênero e representações queer.

palavras-chave:

Design; Queer; Gênero; Normatividade 


\section{Políticas contemporâneas de gênero}

O gênero é entendido por alguns teóricos como uma estrutura social que se relaciona diretamente com os corpos: dentro do contexto da cultura ocidental, a chamada "ordem de gênero" se baseia em diferenças sexuais para enfatizar uma dicotomia rígida nas relações de valor entre homens e mulheres, direcionando cada grupo para o exercício de papéis distintos nas dinâmicas sociais (CONNELL e PEARSE, 2015). Essa ordem binária serve de base para a compreensão sobre as hierarquias entre gêneros, discutidas amplamente por Connell e Pearse (2015) e Butler (2017). O poder que essas estruturas têm sobre a ação individual faz com que o gênero pareça um elemento imutável, no entanto os arranjos de gênero estão em constante mudança ao passo que as práticas humanas desenvolvem novas dinâmicas e situações (CONNELL e PEARSE, 2015). Com isso, essa hierarquia começa a ser questionada uma vez que as questões de gênero têm adquirido protagonismo nas discussões das políticas públicas que buscam reavaliar e redefinir as diversas possibilidades identitárias que os cidadãos podem assumir, entre outras pautas. Considerando que o design é atividade multidisciplinar e que, portanto, reflete, questiona e propõe soluções para as questões sociais e coletivas caracterizadas por sua complexidade inter-relacionada (MORIN, 2014; CARDOSO, 2016), as questões de gênero são ativos no cenário contemporâneo da área.

A oposição "produzir teoria vesus fazer política" tem se demonstrado uma inverdade neste campo (BENTO, 2015), onde os construtos de identidade e gênero servem de ponto de partida tanto para um emergir teórico quanto para a formulação de ações políticas (BUTLER, 2017, p. 223). Entretanto, quando se trata de políticas de gênero, não podemos preconizar a existência de um discurso unificado. A diversidade de movimentos e vertentes - em abordagens feministas, LGBTQIA $+{ }^{1}$, queer ${ }^{2}$, entre outros - contemplam diferentes pautas que vão depender, principalmente, de características culturais e territoriais, refletindo na produção da cultura tanto visual quanto material.

Ao delinear o que pode ser entendido por "perspectiva queer", Colling (2015) favorece seu entendimento ao contrapor os movimentos LGBT mainstream e dissidentes, mostrando as histórias e divergências de ambas formas de ativismo em torno das questões de gênero na América Latina. Ele explica o movimento LGBT mainstream como aquele relacionado aos grupos institucionalizados "que possuem sede própria, vários anos de existência, estrutura legal e uma administração hierarquizada" (COLLING, 2015, 1. 158). Este seria o grupo que teria maior influência junto ao Estado para a promoção de políticas públicas, inserindo pautas com visões globais.

Por outro lado, os movimentos dissidentes são aqueles associados ao ativismo queer e que integram iniciativas não normatizadas, estando posicionados de forma crítica à normalização de comportamentos e processos sociais hierarquizantes (COLLING, 2015). Atentos às diferenças internas, os movimentos de dissidência sexual e de gênero, no contexto da América Latina, nem sempre virão a fazer uso do termo "queer": se torna uma variável a depender do contexto e desenvolvimento histórico de cada local. Isso porque em algumas regiões, a exemplo do Chile, entende-se que a expressão - com sua origem de cunho pejorativo na cultura dos Estados Unidos e hoje ressignificada - não é capaz de contemplar as experiências locais do sul global (COLLING, 2015).

Ainda observando a manifestação queer na América Latina, Pelúcio (2014) denuncia um distanciamento do Brasil com relação às outras visões latinas, argumentando que a questão queer emergiu no Brasil pela via acadêmica e não espontânea como expressão política social. (PELÚCIO, 2014, p. 73-74). De algum modo, podemos fazer um paralelo com a introdução do design no país, que, como tantos outros modelos de outras áreas, foi o resultado de uma conformação estética e funcional eurocêntrica, desconsiderando a realidade e a potência da produção criativa local.

De modo geral, a teoria queer se propõe, em seu ativismo teórico e prático, à contestação de normas a partir de uma visão não-hegemônica. Não se pretende um melhor posicionamento das minorias frente às políticas do sistema social atual, mas sim desconstruir e remodelar a estrutura

\footnotetext{
${ }^{1}$ Sigla referente a lésbicas, gays, bissexuais, transgêneros, travestis, queer, intersexuais, assexuais, entre outras identidades de gênero e orientações sexuais.

${ }^{2}$ Do inglês, significa "estranho", "anormal". O termo, utilizado inicialmente como ofensa contra indivíduos de orientações ou identidades não-normativas, tem sido ressignificado desde a década de 80 como forma de resistência, representando, além de uma identidade, um posicionamento contra a norma (PORTINARI, 2017).
} 
dessas normas majoritárias, isso "não somente em termos de gênero e sexualidade, mas também em termos de raça, classe, nacionalidade" (REA e AMANCIO, 2018, p. 4). Assim, o termo "queer" tem um sentido desconstrutivista e interseccional, sendo inclusive incorporado por proposições decoloniais.

Contudo, ainda que se possa afirmar uma posição política que tem por base expressões da contracultura (não-hegemônicas), o movimento queer e as chamadas dissidências de sexo e gênero não podem ser totalmente categorizadas ou definidas, pois não representam uma imagem unificada, completa e fixa, portanto, são movimentos em constante reconstrução, variando com relação a seus contextos e territórios atuais (COLLING, 2015). Por isso, "o queer escapa da lógica formal, tendo mais a ver com trânsito, fluxo e performatividade, propondo que a categoria humano esteja sempre em aberto, ou seja, que nenhuma sexualidade ou expressão de gênero torne-se polícia de outra" (PERES e TOLEDO, 2011, p.275).

Fazendo uso de um discurso similar ao de Colling (2015), Rea e Amancio (2018) também interpretam o movimento LGBT atual com base em rumos neoliberais e conformistas, no sentido de assimilação de pautas internacionais, vendo uma diferenciação frente a teoria queer, que vem se estabelecendo em uma direção mais subversiva e crítica, seja à normas heterossexuais, brancas ou burguesas. Além disso, reafirmam o caráter impermanente e "em trânsito" das definições sobre teoria e movimento queer. (REA e AMANCIO, 2018, p.4)

Desse modo, uma "perspectiva queer" nos permite perceber outras categorias dissidentes, para além do gênero, que também influenciam nas formas de significação de poder dentro do contexto social de diferentes territórios. Assim como defendido por Gomes (2018), tratar de questões de gênero na América Latina e no Brasil nos exige fazer uso do gênero enquanto categoria de análise decolonial. Isso significa perceber não só a interseccionalidade entre raça, classe e gênero, mas também pensar "como essas categorias juntas, trabalhando em redes, são ao mesmo tempo causa e feito d(n)a criação dos conceitos umas das outras" (GOMES, 2018, p. 71), de maneira que o nosso entendimento sobre gênero é influenciado pela forma como entendemos classe e raça, e o mesmo ocorre de forma recíproca. Se trata de sistemas de opressão que não operam de forma separada dentro das dinâmicas sociais, e não podem ser reduzidos a um só fundamento.

Em resumo, ao tratar de uma perspectiva queer no cenário brasileiro, devemos considerar especialmente as heranças coloniais e a interseccionalidade entre os elementos que constituem as estruturas de poder e hierarquia num contexto local, promovendo uma política de contestação de desigualdades. Como atividade multidisciplinar e constituinte de valores simbólicos, o design adquire contornos relevantes para a compreensão e instauração das relações entre objetos, usuários e sociedade no contexto queer. Ao refletir sobre o papel do design para uma política autônoma de desenvolvimento e o contexto sociopolítico do trabalho projetual, Bonsiepe (2011) reivindica sua rearticulação para um projeto social mais amplo, que dê forma a "uma consciência crítica frente ao enorme desequilíbrio entre os centros de poder e os que são submetidos a eles" (BONSIEPE, 2011, p. 21).

Também com a visão sobre uma maior articulação social no design, Cardoso (2016) estimula o pensamento sistêmico em torno das novas dinâmicas e problemáticas do "mundo complexo", onde os aspectos que o envolvem devem ser tangenciados pela expansão da interdisciplinaridade e de interrelações com novas culturas e valores. O objetivo seria expandir o design para uma maior integração e adaptabilidade às novas dinâmicas sociais, pois apesar de lidar quase sempre com a materialidade das coisas, o design influi também na valorização das experiências e na promoção de interações de ordem social e cultural.

Sobretudo, concordamos que "não existem receitas formais capazes de equacionar os desafios da atualidade" (CARDOSO, 2016, p. 41). O próprio caráter dinâmico e mutável da perspectiva queer revela a complexidade de se tratar a pluralidade das dissidências de sexo e gênero, evitando a imposição de uma cultura única, mundial, hegemônica.

\section{Manifestações queer no design}

Ao se questionar o lugar do design nas políticas de gênero contemporâneas e na emergência do ativismo queer brasileiro, podemos encontrar indicativos para possíveis compreensões de sua complexidade em Thürler et. al. (2017, p. 25): "especificamente falando do queer, notamos que no 
Brasil e na América Latina ele vai além das questões de gênero e sexualidade, marcando lutas sociais contra a normatização em geral". Em convergência a essa lógica, Joost e Bieling (2012) destacam o design como agente de mudanças sociais, estabelecendo como ponto de partida uma "reconfiguração da normalidade", por meio da promoção de diferentes conceitos do "ser normal" ou da crítica a estereótipos. Nesse contexto de problematização das estratégias da normatividade, podemos pensar em queerizar o design, no qual o universo queer é ativo teórico e prático no processo criativo e produtivo fundamentado em particularidades sociais, políticas, éticas, estéticas e simbólicas (PORTINARI, 2017). A materialização de diferenças de gênero e a organização de regimes estéticos, por parte do design, quando observadas por uma perspectiva queer redireciona a questão para o "papel construtivo e normatizador do design tomado como processo social" (PORTINARI, 2017).

Nesse cenário, pensar o design enquanto formulador de sistemas e relações sociais incide sobre o "impulso normativo" caraterizado por Joost e Bieling (2012), que reflete na sociedade determinadas normas de controle e exclusão: o considerado "normal" representa a maioria e se limita a ela, servindo de base para estruturas discriminatórias. Os autores discutem esse conceito relacionando-o ao termo "usabilidade", de muita relevância para qualquer produto, onde normalmente se estabelecem parâmetros - nos processos de desenvolvimento do design - para a construção de problemas e "normalidades", pela expectativa de um comportamento correto único. Nesse contexto, eles identificam a necessidade de uma maior abertura à "diversidade" no design, reafirmando sua natureza não apenas prática como também de fenômeno social (JOOST e BIELING, 2012)

Numa visão próxima, Costanza-Chock (2018) afirma que o design precisa operar de acordo com ideais democráticos de inclusão e de justiça social. Ela percebe ainda hoje uma realidade onde o impacto das decisões de projeto que envolvem, por exemplo, cultura visual e estruturas de sistemas políticos, recaem mais sobre aqueles que tiveram menos influência nas decisões. Isso significa que as vozes centrais nos processos de design muitas vezes não representam os grupos diretamente afetados, o que pode levar tanto à manutenção de visões universais e hegemônicas quanto à invisibilização de determinadas comunidades.

Como membro do comitê diretor da organização Design Justice Network, Costanza-Chock (2018) apresenta um delineamento do que significa integrar ao design os discursos de interseccionalidade, aos quais associa também ao conceito de "matrix de dominação" de Patricia Hill Collins. Os termos são compreendidos de formas particulares: enquanto interseccionalidade trata do modo como diferentes opressões operam juntas na produção de injustiças, a matrix de dominação foca em entender, independente das opressões interseccionalizadas, os domínios de poder que se repetem, seja de modo estrutural, disciplinar, hegemônimo, interpessoal (COLLINS, 2000, p. 18). Assim, define-se o "design justice" enquanto vertente:

Design justice é um campo teórico e prático que se preocupa em como o design dos objetos e sistemas influenciam a distribuição de riscos, prejuízos e benefícios entre vários grupos de pessoas. Design justice foca nas formas pelas quais o design reproduz, é reproduzido, e/ou desafia a matrix de dominação (supremacia branca, heteropatriarcado, capitalismo e colonialidade). Design justice é também um movimento social crescente que busca garantir uma maior equidade na distribuição de benefícios e ônus do design; uma justa e significativa participação em decisões projetuais; e reconhecimento de tradições, conhecimentos e práticas de design em comunidades. (COSTANZA-CHOCK, 2018, p. 533, tradução nossa) ${ }^{3}$

\footnotetext{
3 "Design justice is a field of theory and practice that is concerned with how the design of objects and systems influences the distribution of risks, harms, and benefits among various groups of people. Design justice focuses on the ways that design reproduces, is reproduced by, and/or challenges the matrix of domination (white supremacy, heteropatriarchy, capitalism, and settler colonialism). Design justice is also a growing social movement that aims to ensure a more equitable distribution of design's benefits and burdens; fair and meaningful participation in design decisions; and recognition of community based design traditions, knowledge, and practices"
} 
De modo geral, projetos que conduzem a uma transformação social positiva devem considerar como relevante não apenas quem está envolvido no processo, mas quem se beneficia e quem pode estar sendo prejudicado pelas soluções geradas. A Design Justice Network (2020) aponta para o perigo das "boas intenções" em projetos que acabam reforçando preconceitos e discriminações contra determinados grupos, apresentando como exemplo o aplicativo Giggle: uma rede social exclusiva para mulheres lançada no início de 2020, com a intenção de promover um espaço de interação seguro e livre de assédio. Contudo, o cadastro feito por reconhecimento facial se utiliza de estereótipos para definir rostos masculinos e femininos, e assim realizar a triagem sobre quem pode ou não ingressar na plataforma. Esse tipo de tecnologia põe em questão as percepções de gênero por parte dos desenvolvedores, que se constroem por princípios normativos, limitados a uma afirmação de gênero exclusivamente por meio de características faciais (DESIGN JUSTICE NETWORK, 2020).

A manutenção de padrões de normalidade sobre gênero e corpo no design pode se manifestar de diversas formas. Quando tratamos de expressões de gênero em objetos do nosso cotidiano, Buchmüller (2016) identifica dois modos práticos do design nas últimas décadas: um deles pautado na crença de que existem dois gêneros a serem demarcados nos objetos, por meio de cores, formas, atributos simbólicos, entre outros; e o segundo indicado pelo abandono do uso de qualquer elemento considerado "generificado" na construção do projeto, sendo o gênero um fator ignorado. O primeiro caso, como exemplificado por Borges (2017), pode ser visto na normatização de identidades binárias que se manifestam em brinquedos infantis. Estes comumente se utilizam de padrões simbólicos e estéticos como fator de diferenciação dos objetos direcionados para cada público, feminino e masculino. Um reflexo disso é que "a partir da utilização de signos específicos, o design de produtos constrói representações sociais que instituem como padrão de normalidade o corpo generificado em oposição binária, branco e heterossexual" (BORGES, 2017, p.11), por isso a interseccionalidade surge como fator determinante de mudança, para estabelecermos relações entre diferentes marcadores sociais e confrontar esses processos de normatização.

Quando se trata de dissidências de sexo e gênero no design, Buchmüller (2016) questiona de que maneira podemos, enquanto designers, projetar para "usuários que não conhecemos", e evoca o uso de metodologias mais participativas como solução. Isso leva à uma reflexão sobre quem, majoritariamente, representa as produções de design no Brasil. Observamos na história do design, de acordo com Borges (2017), as transformações nos modelos de produção industrial, que sequenciaram mudanças sociais nos hábitos de consumo, e tornaram os objetos elementos de demarcação de identidade e de personalidade individual. Contudo, ao longo da ascensão do design no século XIX “o designer compartilhava dos mesmos gostos e valores da burguesia, e consequentemente, sua prática reproduzia os ideais das classes dominantes" (BORGES, 2017, p. 48), estabelecendo uma cultura de valorização de um "homem universal", uma visão hegemônica.

Essa perspectiva individualista acaba por ignorar que o design é um processo de representação, e seu significado não pode ser destacado do contexto histórico, político e econômico. Uma história do design que considera um significado fixo para seus produtos (aquele que o designer lhe atribuiu) acaba negando que o significado do design é polissêmico, e que mesmo a definição do que é ou não é design é produto de relações de poder. Uma história centrada em uma narrativa individual, burguesa, masculina e europeia, que sustenta a ideia de um significado único para encobrir o fato de que os códigos produzidos nesses contextos são os códigos das classes dominantes. [...]

Em uma sociedade atravessada por relações de poder desiguais, e onde fatores como gênero, raça, sexualidade e classe social produzem hierarquias sociais, os códigos através dos quais o design é constituído e interpretado são os códigos de quem está posicionado nos níveis superiores dessas hierarquias. (BORGES, 2017, p. 49)

Como forma de evitar um discurso que reforce normas sobre corpo e gênero, a abordagem de "gender-sensive design" de Buchmüller (2016), implica em questões similares ao "design justice" de Costanza-Chock (2018). Ambos se propõem a incorporar no processo de pesquisa e desenvolvimento questões sobre quem está envolvido (grupos de interesse, usuários), quem ou o que é incluído e excluído, quem está responsável pela tomada de decisões, entre outros. Sobretudo, aponta-se também 
uma cultura disciplinar atenta à que fontes de conhecimento e modelos de representação são utilizados, que poderes e relações de gênero existem, e quais políticas e valores estão envolvidos.

\subsection{Relações entre design, corpo e identidade}

Outro modo de centralizar críticas de gênero no design pode se dar por meio de percepções sobre o corpo e sua inserção em diferentes processos coletivos. Podemos citar como exemplo o design de moda que, no contexto da cultura queer, percebe o corpo enquanto performance - capaz de alcançar sentidos que rompem com a normativa da ordem de gênero - e constrói expressões de diversidade marcadas também por meio de artefatos (ZAPATA e OLIVEIRA JR, 2017). Na área de design de produto o corpo é elemento que fundamenta projeções para a configuração de produtos que por sua vez são extensões do próprio corpo. Na abordagem de Rui Dias (2014) sobre as compreensões e ligações objeto-corpo, as áreas projetuais tiveram visões historicamente mais consolidadas no que se refere às proporções e medidas, a exemplo dos modelos antropométricos e ergonômicos. Em paralelo, o autor apresenta o desenvolvimento, na história do design, de considerações sobre aspectos cognitivos, emocionais e simbólicos que tornou possível entender outras dimensões dos objetos e dos corpos com os quais se relacionam, em diferentes níveis de interação. Discutindo a amplitude dessas relações, ele argumenta que o corpo está aberto a possibilidades múltiplas para além de sua corporeidade (DIAS, 2014, p. 302).

Dessa forma, o corpo enunciado participa das e responde às dinâmicas sociais. Podendo ser percebido para além dos modelos padronizados (anatômicos, ergonômicos), considerando-o como um campo de investigação múltiplo, enredado em práticas sociais, como abordado por Connell (2016), e investido de poderes, como tratado por Foucault (2014). Para aprofundar essa perspectiva, Dias (2014) desenvolve a definição de um "corpo ator", que seria "social e culturalmente construído por essas dinâmicas, mas que também se constrói a si mesmo". Sinaliza, então, a sujeição dos corpos a grupos de pertença (gênero, classe, raça, etc.) e a normas de comportamento e valores, sendo o design agente ativo nessas configurações. Connell (2016) descreve esse processo a partir do conceito de embodiment, ou "corporificação social", onde se estabelece um vínculo de participação dos corpos nas dinâmicas sociais, e também de um impacto dessas dinâmicas sobre os corpos.

Em retrospecto, Foucault (2014) submete uma análise sobre o funcionamento, especificamente, dos mecanismos de poder, que articulam a sociedade por ordens de controle, seja de repressão ou estimulação, sobre os corpos. Isto é, mecanismos rígidos instituídos pelo Estado, a exemplo de ferramentas políticas e econômicas, dispositivos e objetos, utilizados para disciplinar os corpos em normas de práticas e dinâmicas sociais.

A partir do traçado de Gomes (2018) sob uma perspectiva política e sociológica, temos o gênero não só como um dos elementos constitutivos das relações sociais, mas também como uma categoria de significação dessas relações de poder e hierarquia nas quais estamos inseridos. Nesse sentido, Butler (2017) teoriza sobre o caráter performativo do gênero, como capaz de produzir uma série de efeitos: a forma como agimos, andamos, nos comunicamos, consolidam impressões de "ser homem" ou "ser mulher". É um fenômeno constantemente produzido e reproduzido, que constitui nossas identidades pessoais, sustentado sobre uma matriz binária que parte das hierarquias de poder.

Um reflexo dessa estrutura de poder inflexível, na visão de Butler (2017), é que as reações e construções que subvertam as normas acabam sendo retaliadas por meio de marginalização e invisibilização social dentro de uma cultura de dominação e opressão. Contudo, para Zapata e Oliveira Jr. (2019), o design em diálogo com a cultura queer tem se mostrado um ponto de ruptura possível nessa cultura, especificamente no design de moda que opera na construção de multiplicidades e consegue questionar o caráter transitivo e político dos objetos quando relacionados ao corpo.

Com base nas novas demandas sociais que emergem, tratadas pela teoria queer, entender o corpo como lugar de inscrição de técnicas, práticas sociais, comportamentos, valores e signos, a partir da influência de meios de exercício de poder (instituições, leis, objetos, etc.), é essencial para tratarmos de questões de gênero no campo do design, uma vez que abordar gênero requer abordar também o corpo.

Nesse sentido, a ideia de corporeidade, tratada por Connell (2016), simboliza todo o conjunto de ações e dinâmicas sociais que envolvem as relações entre os indivíduos e as sociedades, principalmente nas considerações sobre gênero e identidade. Esse conceito entra em consonância com 
a visão de "corpo ator" no design, elaborada por Dias (2014), e nos atenta para o valor dos contextos socioculturais - sobretudo em perspectivas decoloniais - na atividade projetual, indicando uma consideração sobre a complexidade dos tecidos sociais e das relações interpessoais e coletivas.

Entendendo o design como campo múltiplo, de entrecruzamento de diferentes práticas e espaços (PORTINARI, 2017), as novas configurações sociais que emergem demandam, portanto, maior sensibilidade sobre aspectos e impactos dos regimes de normatividade no design. De modo mais amplo, uma necessidade de atualização contínua sobre as demandas contemporâneas, evoluindo da concepção do design voltado para a emergência de necessidades - muitas vezes criadas para atender às demandas dos lucros das grandes corporações - para o design como estratégia de viabilização do bemestar social inclusivo (MARGOLIN, 2014, p. 157), sobretudo por meio de contestação de práticas hegemônicas. A ação do designer deve, assim, incorporar à sua atividade a responsabilidade de uma prática projetual que contribua para a potencialização da consciência crítica e dos valores coletivos e diversos, e não apenas para uma aplicação pragmática de aspectos técnicos (MARGOLIN, 2014, p. 17). Neste sentido, se torna urgente o valor de um olhar histórico (e decolonial) atento às contextualizações e complexidades sociais.

\section{Fronteiras e expansões do devir-queer}

O pós-modernismo está fundamentado na possibilidade de uma recodificação estética e, consequentemente, no pluralismo, pela combinação de diversos estilos na arte, na arquitetura (FOSTER, 1996), e por extensão no design (BOMFIM, 1998, p. 112). Assim, favorecendo experimentações estéticas que ampliaram ainda mais o horizonte subjetivo do design, para além da dimensão funcional e utilitária associadas ao progresso e ao racional da verdade absoluta (JULIER, 2004, p. 169). Ao mesmo tempo, com o advento das possibilidades criativas proporcionadas pela ascensão da tecnologia em produtos revolucionários como o computador de uso individual, que possibilitou maior autonomia e criatividade às pessoas (JULIER, 2004, p. 19), emergiram concomitantemente novas abordagens para o design contemporâneo com foco no humano (MORAES, 1997, p. 109), diverso da concepção do 'usuário' que se refere a uma condição de uso das qualidades utilitárias. Assistimos então ao surgimento de novas propostas e conceitos como "design emocional" (NORMAN, 2008), "design co-participativo", design de experiência (BENZ, 2015) e mais recentemente diversas possibilidades que vão desde a proposta de design crítico e especulativo (WARD, 2019) até a ascensão da crítica ao design eurocêntrico e patriarcal, expressos no design decolonial (SILVA e LESSA, 2019; ABDALA e SIQUEIRA, 2019).

Neste contexto, o design também se voltaria para as fronteiras abertas pelo pós-modernismo à teoria e à prática queer (JARY e JARY, 2000) proporcionando visibilidade e impacto por meio das redes sociais. Ao combinar incorporação de novas identidades de gênero com acesso à tecnologia, o design assume uma dimensão diferente daquela que, embora ainda prevaleça, não mais se impõe como hegemônica: a da exclusividade para um público que pode consumir design. Uma fresta - que se expande continuamente - foi aberta para que o design contemporâneo se tornasse cada vez mais democrático. E por essa fresta passa com forte luminosidade os diversos gêneros e identidades dissidentes, suas características e suas demandas de reconhecimento e oportunidades de design. Como consequência, se torna inevitável a revisão dos seus fundamentos ontológicos e de seus alcances simbólicos (ABDALA e SIQUEIRA, 2019).

Considerando a curta história do design - da criação tangível utilitária da revolução industrial para a concepção intangível da experiência pelo entretenimento da revolução $4 \mathrm{G}$ - podemos atestar a rápida transição da valorização do produto para a valorização do homem em toda sua complexidade (MORAES, 1997, p. 116). Do foco na máquina estática para a construção de mundos onde habita uma diversidade cada vez mais complexa de seres e saberes. O design ganha cada vez mais contornos de inevitabilidade cotidiana não apenas material, mas também de concepção de mundo e de significados construídos de forma compartilhada, onde a figura do designer como único criador/emissor de produtos/mensagens se transfigura em um vetor que constitui mecanismos para proporcionar ao indivíduo a possibilidade de exercer não apenas seu potencial criativo, mas também expressar sua individualidade em toda sua complexidade, seja sexual, emocional, racional e/ou criativa. 
Quando Dias (2014) trata do corpo, em sua relação com os objetos, como lugar de construção da identidade pessoal, ele assume o potencial de fragmentação das identidades contemporâneas, sempre em devir. Da mesma forma, centraliza os produtos de consumo como ativos no processo de construção identitária pessoal, grupal e social, por fazerem parte de uma dimensão comunicacional. Os objetos não são apenas parte de um processo de agenciamento funcional dos corpos e identidades, eles são também prolongamentos simbólicos, e, portanto, considerar as dimensões sociais e culturais nos direciona para uma compreensão do corpo substancialmente mais completa (DIAS, 2014).

Segundo Portinari (2017), a convergência dos estudos queer com a vertente pós-colonial dos estudos culturais trouxe novas reivindicações de grupos dissidentes de sexo e gênero, e potencializou abordagens interseccionais. Dentro disso, o design representa, além de uma ferramenta de libertação para expressão de individualidades, um mediador para apropriação de lugares de abjeção e dissidências como forma de resistência a normatizações. Entendemos aqui o lugar de abjeção como “precisamente aquelas zonas 'inóspitas' e 'inabitáveis' da vida social que são, não obstante, densamente povoadas por aqueles que não desfrutam do status de sujeito, mas cujo habitar sob o signo do 'inabitável' é necessário para que seu domínio de sujeito seja circunscrito" (BUTLER, 1993, p. 3, tradução nossa $)^{4}$. Essa conceituação deixa claro os postos de hierarquia social com base nas construções de sexo/gênero - e também, de modo interseccional, de classe e raça - que se propõem em estabelecer uma matriz normativa, entendida como forma de humanização de determinados corpos e como produto da colonialidade (GOMES, 2018).

Refletindo sobre esse processo de hierarquização, Zapata e Oliveira Jr (2017) analisam o "devir-queer" no design por uma dimensão ontopolítica, onde o design é agenciador das complexas expressões de gênero e identidade, sempre em trânsito, sejam elas inseridas nos regimes estéticos dominantes, ou sejam elas deslocadas das expectativas normativas. De toda forma, fortalecer relações positivas de pertença nos grupos dissidentes, por meio da criação de produtos com valores simbólicos e comunicacionais democráticos, dilui as experiências de estigmatização que se estendem nos diversos espaços, serviços e processos das dinâmicas sociais (PERES e TOLEDO, 2011).

Apesar da dimensão estética das subjetividades identitárias terem se configurado nos moldes das classes dominantes durante a ascensão da sociedade industrial, delineando e materializando estruturas hierárquicas numa "nova forma de regulação da coesão social" (PORTINARI, 2017, p. 11), o agenciamento da norma no cenário contemporâneo tem se reestruturado pelas teorias e práticas queer. Na formulação de um "design queer", logo, pretende-se não uma intervenção técnica sobre questões metodológicas práticas, mas sim uma ampliação de discursos de enfrentamento nos moldes teóricos de reflexão crítica do campo. Assim:

Vale reiterar que não poderia tratar-se de uma "aplicação", pela via do design, das teorizações queer, nem de uma proposta de submeter o design a uma espécie de intervenção queer. Trata-se antes de uma contaminação do design pelo queer e de uma instrumentalização do queer pelo design. Aqui estamos nos apropriando de toda a carga pejorativa dessa palavra quando associada ao queer - patologia, peste, ameaça - para ressignificá-la: deixar-se contaminar pelo queer é problematizar a normatividade de dentro, estranhar as suas práticas e os seus efeitos, e inocular ali uma possibilidade de pensar e viver "outramente".

Queerizar é problematizar a normatividade e potencializar a diferença, lá onde elas se produzem: nos dispositivos de saber e de poder, na performatividade dos discursos e das práticas, na materialização e partilha das (in)visibilidades - e nos seus pontos de fragmentação e fissura. Essa problematização se dá de diversas formas, abrindo novas possibilidades de agenciamento crítico. (PORTINARI, 2017, p. 14)

Portinari (2017) nos apresenta também, à luz de Rancière (2012), uma inflexão sobre "novas formas de habitação do mundo sensível", propondo o design como responsável pela redefinição de partilhas do espaço comum, compartilhado. Isso reafirma a ideia anterior de inevitabilidade cotidiana

\footnotetext{
4 "[...] precisely those "unlivable" and "uninhabitable" zones of social life which are nevertheless densely populated by those who do not enjoy the status of the subject, but whose living under the sign of the "unlivable" is required to circumscribe the domain of the subject".
} 
no design para estruturação de lugares de pertença para além dos regimes normativos e para a concepção de significados e dinâmicas sociais, discutindo a "materialidade inelutável das produções do design, pelo viés de seus efeitos na materialização performativa de corpos, subjetividades, identidades e diferenças sociais normatizadas" (PORTINARI, 2017).

\section{0 design em trânsito}

Nos sistemas de materialização de regimes normativos e de representações simbólicas de gênero consolidados por mediação do design, encontramos novas propostas de abertura para se discutir processos contra-hegemônicos no campo, pela ótica decolonial e interseccional. Além das recentes abordagens que emergem com foco no humano - como o design decolonial, design crítico e especulativo, design emocional, entre outros abordados neste artigo - vemos novas propostas de design que apontam para uma visualização específica das questões de gênero por uma perspectiva queer. Essas propostas se revelam na ação direta de queerizar o design, impregnando a teoria, metodologia e prática com problematizações sobre a normatividade (PORTINARI, 2017); na proposta humanista do design sensível às questões de gênero ("gender-sensitive design") questionando a posição de poder do design como centro da cultura de consumo, e capaz de manifestar ou gerar mudanças com responsabilidade social no reconhecimento da diversidade de gêneros (BUCHMÜLLER, 2016); e no design justo ("design justice"), onde o design se apresenta como chave de libertação coletiva por meio de uma análise interseccional da reprodução de desigualdades nos processos projetuais (COSTANZA-CHOCK, 2018).

Esses novos contornos articulam mudanças nas visões absolutistas sobre gênero, integrando ao design os atuais desafios de transformação e subjetivação do sujeito, dos objetos e dos poderes. Um olhar atento às dissidências queer permite ao designer examinar o caráter dinâmico das complexidades sociais, ligadas às estruturas de hierarquia, dominação e regulação dos corpos. Como consequência, impõe-se ao design a necessidade substancial da revisão de valores que, de certa forma, têm sido redimensionados, provocando um deslocamento do puramento pragmático, objetivo e orientado sob uma perspectiva ocidental e patriarcal, para diversas dimensões e camadas que emergem a partir da presença física e da expressão de fala das possibilidades múltiplas de gênero e visões de mundo.

Essa perspectiva instaura a urgência de redefinir conteúdos apreendidos nas diversas formações do designer - e consequentemente na prática da atividade - deslocando o foco na especialização que aprofunda o isolamento de áreas que devem convergir no processo de design como Estética, Ergonomia, Comunicação, entre outras - para a abordagem verdadeiramente transdisciplinar e convergente, conectando instantaneamente os conteúdos e favorecendo a compreensão da complexidade intrínseca na interação entre o produto e o humano. Ou seja, considerando a complexidade do humano, o produto deve operar no campo também de sua inevitável complexidade, incluindo agora o que a contemporaneidade impõe como fator de sua natureza: a identidade de gênero e suas dissidências. 


\section{Design and Queer Dissent: gender considerations in design}

Abstract: This article presents considerations about design and queer culture as part of research in progress. Initially, we contextualize about contemporary gender policies, presenting questions about the binary order, gender hierarchies, and the plurality of activisms, also pointing out how these issues relate to the field of design. Approaching gender dissidences as intrinsic to the relations of intersectionality and decoloniality, we address design as a political means of contestation front of queer agendas and perspectives. Thus, discussing the normative aesthetic regimes and the way in which design operates facing hegemonic standards, presenting some new proposals and perspectives that have been taking place in the field. The intention is to perceive, in the ascent of new discourses, the inevitability of gender issues in design, due to its role and impact on symbolic representations of gender and the materialization of normative regimes. Considering, through contemporaneity, the human factor in its complexity, it is needful a new perspective on gender dissent and queer representations in design.

Keywords: Design; Queer; Gender; Normativity

\section{Referências bibliográficas}

ABDALA, M.; SIQUEIRA, N. Fazer e pensar design em um mundo em transição: Decolonialidade e design como articulação simbólica. In: Anais do $9^{\circ}$ CIDI e $9^{\circ}$ CONGIC. Belo Horizonte: SBDI, 2019.

BENTO, Berenice. Apresentação. In: COLLING, Leandro. Que os outros sejam o normal: tensões entre movimento LGBT e ativismo queer. Prefácio. Salvador: EDUFBA, 2015. I. 64-150. ePUB

BENZ, Peter. Experience Design. London: Bloomsbury, 2015.

BOMFIM, Gustavo A. Ideias e Formas na História do Design. Editora Universitá UFPB, 1998.

BONSIEPE, Gui. Design, Cultura e Sociedade. 1ª. ed. São Paulo: Blucher, 2011.

BORGES, Laila. As formas que moldam gêneros: o design como tecnologia de gênero no projeto de brinquedos infantis. Dissertação (Mestrado em Gênero) - Faculdade de Filosofia e Ciências Humanas, UFBA. Salvador, 2017.

BUCHMÜLLER, Sandra. How to Design in a Social Responsible and Gender Sensitive Way? Palesta proferida no KISDtalks, Köln International School of Design, Köln, 2016. Disponível em: <https://kisd.de/en/termine/how-to-design-in-a-social-responsible-and-gender-sensitive-way/>. Acesso em 28 jul. 2020.

BUTLER, Judith. Bodies that matter: on the discursive limits of "sex". New York: Routledge. 1993.

BUTLER, Judith. Problemas de gênero: feminismo e subversão da identidade. Tradução: Renato Aguiar. 13a. ed. Rio de Janeiro: Civilização Brasileira, 2017.

CARDOSO, Rafael. Design para um mundo complexo. São Paulo: Ubu, 2016.

COLLING, Leandro. Que os outros sejam o normal: tensões entre movimento LGBT e ativismo queer. Salvador: EDUFBA, 2015. ePUB.

COLLINS, P. H. Black feminist thought: knowledge, consciousness, and the politics of empowerment. 2. ed. New York: Routledge, 2000.

CONNELL, Raewyn. Gênero em termos reais. Tradução: Marília Moschkovich. São Paulo: nVersos, 2016. 
CONNELL, R.; PEARSE, R. Gênero: uma perspectiva global. Tradução: Marília Moschkovich. São Paulo: nVersos, 2015.

COSTANZA-CHOCK, Sasha. Design Justice: towards an intersectional feminist framework for design theory and practice, p. 529-540. In: Design Research Society International Conference [Proceedings of DRS2018, v.2]. Limerick: Design Research Society, 2018.

DESIGN JUSTICE NETWORK. If We Want Design to be a Tool for Liberation, We'll Need More Than Good Intentions. AIGA Eye on Design, 22 jul. 2020. Disponível em:

$<$ https://eyeondesign.aiga.org/for-design-to-truly-be-a-tool-for-liberation-were-going-to-need-morethan-just-good-intentions/>. Acesso em: 22 jul. 2020.

DIAS, Rui H. M. Design de produto e corpo humano: ligações objeto-corpo na contemporaneidade. 2014. Tese (Doutorado em Design) - Faculdade de Arquitetura, Universidade de Lisboa. Lisboa, 2014.

FOSTER, Hal. Recodificação. São Paulo: Casa Editorial Paulista, 1996.

FOUCAULT, Michael. História da sexualidade: a vontade de saber. São Paulo: Paz \& Terra, ed. 9, vol. 1, 2014.

GOMES, Camilla. D. M. Gênero como categoria de análise decolonial. Civitas, Porto Alegre, v. 18, n. 1, Janeiro-Abril 2018. p. 65-82.

JARY, David; JARY, Julia. Collins Dictionary of Sociology. Glasgow: Harper Collins, ed. 3, 2000.

JOOST, G.; BIELING, T. Design contra a Normalidade. V!RUS, São Carlos, n. 7, Junho 2012.

JULIER, Guy. Design Since 1900. London: Thames \& Hudson, 2004.

MORAES, Dijon De. Limites do Design. São Paulo: Studio Nobel, 1997.

MORIN, Edgar. A Cabeça Bem-Feita. Rio de Janeiro: Bertrand, 2014

NORMAN, Donald. Design Emocional. Rio de Janeiro: Rocco, 2008.

PELÚCIO, Larissa. Traduções e torções ou o que se quer dizer quando dizemos queer no Brasil?

Revista Periódicus, Salvador, n. 1, Maio-Outubro 2014. p. 68-91.

PORTINARI, Denise. Queerizar o Design. Arcos Design, Rio de Janeiro, v. 10, n. 1, Outubro 2017. p. $1-19$.

PERES, Willian S.; TOLEDO, Lívia G. Dissidências Existenciais de Gênero: resistências e enfrentamentos ao biopoder. Psicologia Política, Porto Alegre, v. 11, n. 22, Julho-Dezembro 2011. p. 261-277.

RANCIÈRE, Jacques. O destino das imagens. Rio de Janeiro: Contraponto, 2012.

REA, Caterina A.; AMANCIO, Izzie M. S. Descolonizar a sexualidade: Teoria Queer of Colour e trânsitos para o Sul. Cadernos Pagu, Campinas, n. 53, 2018.

SILVA, Sâmia B. E.; LESSA, Washington D. Modernização, progresso e desenvolvimento: desafios para o design na construção de perspectivas locais contra-hegemônicas, p. 561-569. In: Anais do 70

Simpósio Design Sustentável [Blucher Design Proceedings, v.6, n.3]. São Paulo: Blucher, 2019.

THÜRLER, D.; TRÓI, M. D.; GARCIA, P. C. Dossiê Artivismo: outras cenas de enfrentamento, ontem e hoje. Cult, São Paulo, n. 226, Agosto 2017. p. 24-27

WARD, Matt. Critical about Critical and Speculative Design. SpeculativeEdu, 23 jul. 2019. Disponível em: <https://speculativeedu.eu/critical-about-critical-and-speculative-design/>. Acesso em: 04 ago. 2020.

ZAPATA, M.; OLIVEIRA JR, N. H. Design de moda e cultura Queer: o devir-drag como expressão de gênero. Revista D.: Design, Educação, Sociedade e Sustentabilidade, Porto Alegre, v. 9, n. 2, 2017. p. 80-91. 